\title{
Transcatheter therapies for mitral regurgitation
}

A professional society overview from the American College of Cardiology, The American Association for Thoracic Surgery, Society for Cardiovascular Angiography and Interventions Foundation, and The Society of Thoracic Surgeons

\author{
Writing \\ Committee \\ Members: \\ Patrick T. O'Gara, MD, FACC, Co-Chair, ${ }^{\mathrm{a}}$ John H. Calhoon, MD, Co-Chair, ${ }^{\mathrm{b}}$ \\ Marc R. Moon, MD, FACC, ${ }^{\mathrm{c}}$ and Carl L. Tommaso, MD, FACC, FSCAI ${ }^{\mathrm{d}}$
}

\section{TABLE OF CONTENTS}

Preamble. .837

1. Introduction .838

1.1. Key Questions. .838

2. Mitral Valve Surgery. .838

3. Critical Components for Successful Transcatheter MR Therapies. . .839

3.1. Heart Team .839

3.1.1. Role of the Primary Cardiologist .839

3.1.2. Role of the Imaging Specialist(s). .839

3.1.3. Role of the Heart Valve and Heart Failure Specialist .840

3.1.4. Role of the Interventional Cardiologist......840

3.1.5. Role of the Cardiac Surgeon.........................840

3.2. Specialized Facilities............................................ 840

3.2.1. Regional Heart Centers................................840

3.2.2. Procedure Setting......................................8 840

4. Literature Review........................................................... 841

4.1. Clinical Trials in the United States.......................841

4.2. European Registry and Observational Studies....841

4.3. Other Transcatheter Mitral Valve

Technologies .842

5. Operator Training. 842

6. Protocols for Care .842

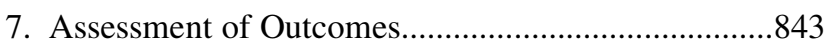

8. Summary and Recommendations...............................843

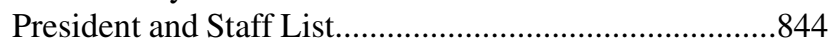

References. .844
Appendix 1. Author Relationships With Industry and Other Entities (Relevant).

Appendix 2. Peer Reviewer Relationships With Industry and Other Entities (Relevant). .846

\section{PREAMBLE}

Transcatheter aortic valve replacement (TAVR) has transformed the care of patients with aortic stenosis. The dissemination of this technology after its approval in the United States in the wake of a pivotal randomized trial ${ }^{1,2}$ has thus far proceeded in a thoughtful and circumspect manner, guided by a coalition of stakeholders dedicated to the delivery of high-quality, patient-centered care. It is anticipated that a number of transcatheter therapies for mitral regurgitation (MR) will also become available for clinical use in selected patients. As an example, the MitraClip device (Abbott Vascular, Santa Clara, Calif) was approved October 24, 2013, for the reduction of significant $(\geq 3+)$, symptomatic, degenerative MR in highly anatomically selected patients considered by an experienced heart team to be at prohibitive risk for mitral valve surgery. Other transcatheter approaches in development include mitral annulus-based therapies, transapical neochordal implants, valve-in-valve and valve-in-annuloplasty ring therapies, and valve replacement therapies. A process similar to that adopted for TAVR is proposed to ensure that such innovative treatments are introduced into medical practice in the United States with appropriate safeguards. ${ }^{3}$ The American College of Cardiology (ACC), the American Association

This article is copublished in The Annals of Thoracic Surgery, Catheterization and Cardiovascular Interventions, and the Journal of Thoracic and Cardiovascular Surgery.

Copies: This document is available on the World Wide Web sites of the American College of Cardiology (www.cardiosource.org), the American Association for Thoracic Surgery (http://www.aats.org), the Society for Cardiovascular Angiography and Interventions (http://www.scai.org), and The Society of Thoracic Surgeons (http://sts.org). For copies of this document, please contact Elsevier Inc. Reprint Department: fax, 212-633-3820; E-mail, reprints@elsevier.com.

Permissions: Modification, alteration, enhancement, and/or distribution of this document are not permitted without express permission of The American Association for Thoracic Surgery. Please contact Elsevier's permission department at healthpermissions@elsevier.com.

$0022-5223 / \$ 36.00$

Copyright (C) 2014 by The American Association for Thoracic Surgery, American College of Cardiology Foundation, the Society for Cardiovascular Angiography and Interventions Foundation, and The Society of Thoracic Surgeons.

http://dx.doi.org/10.1016/j.jtcvs.2013.12.002 
for Thoracic Surgery (AATS), The Society of Thoracic Surgeons (STS), and the Society of Cardiovascular Angiography and Interventions (SCAI) Foundation have collaborated to write this overview to set the stage for an ensuing series of documents, to be joined by other professional societies, and to address the issues critical to the appropriate integration of transcatheter MR therapies into the care of selected patients with this disorder. In accordance with the ACC's policy on relationships with industry and other entities (RWI), relevant author disclosures are included in Appendix 1 of this document. In the spirit of full disclosure, authors' comprehensive RWI information, which includes RWI not relevant to this document, is available online as a data supplement to this document (http://jaccjacc.cardiosource.com/acc_documents/2013_ TTMR_Comprehensive_Author_Disclosure_Table.pdf). RWI restrictions do not apply to participation in the external peer review process for clinical documents, in order to ensure that a variety of constituencies/perspectives inform the final paper. However, for purposes of full disclosure, all relevant RWI for reviewers, as well as their individual affiliations, are published in Appendix 2. Final review and approval of the document was provided by the respective boards of the 4 professional societies. These organizations are committed to providing guidance on key issues having an impact on clinical care and believe this document will help frame subsequent discussions regarding such technology as it continues to evolve.

\section{INTRODUCTION}

Catheter-based therapies for valvular heart disease, including balloon valvuloplasty, have been in clinical use for over 3 decades. More recently, transcatheter valve replacement technologies have dramatically altered the approach to children and adults with congenital or postsurgical pulmonic valve disease and to adults with degenerative aortic stenosis. Using the lessons learned from the release of these transformational technologies, this document seeks to highlight the critical issues surrounding adult transcatheter MR therapies to properly align the interests of all relevant stakeholders, including primary care physicians; patients and their families; proceduralists (interventional cardiologists, cardiac surgeons); heart valve, heart failure, and imaging experts; general and geriatric cardiologists; other heart team members; and regulators, payers, professional societies, and industry. In order to promote the expansion of this technology to allow for best patient outcomes, new guidelines and requirements for training, operator credentialing, and institutional policies will be developed.

\subsection{Key Questions}

1. How will this technology be regulated and by what authority?
2. Will the technology be available in all centers to all interested parties, or will it be restricted to specialized centers? If the latter, how will these centers be specified? What constitutes a heart valve center of excellence? Are the characteristics of a valve reference center the same for aortic and mitral disease?

3. What training will be required for interventional cardiologists and surgeons, and how will it be accomplished? Will the training be the same for cardiologists and surgeons? What criteria will be utilized to grant procedural privileges?

4. What clinical, procedural, administrative, and followup data will be collected and by what mechanism to ensure rigorous assessment of outcomes across centers and provide a framework for comparative effectiveness research and cost-effectiveness assessment? How will patient cohorts that are most and least likely to benefit from this technology be identified?

5. What mechanisms will exist to allow for the careful extension of this technology to the treatment of other groups of patients not included or studied in the initial, randomized clinical trials?

6. How will this technology be reimbursed? Will there be a national coverage determination?

Answers to these questions are complex and influenced in large measure by the number of interested stakeholders. Transcatheter treatment of MR is technically challenging and thus far of limited scope. Maintaining the best interests of patients constitutes the driving force behind any initiative of this type.

\section{MITRAL VALVE SURGERY}

MR can result from abnormalities in the structure and/ or function of 1 or more of the 4 components of the mitral apparatus (leaflets, annulus, chordae tendineae, and papillary muscles/left ventricular [LV] myocardium). Primary MR refers to abnormalities of the leaflets and is most commonly due to myxomatous degeneration, especially in developed countries. With secondary or functional $\mathrm{MR}$, the leaflets are usually normal, and the regurgitation occurs as a consequence of adverse LV remodeling, with papillary muscle displacement, leaflet tethering, and annular dilatation. The prevalence of moderate to severe mitral valve disease (more often regurgitant rather than stenotic) increases as a function of age and exceeds that of aortic valve disease on both a community and population level when assessed by echocardiography. ${ }^{4}$ Prognosis with MR differs as a function of both etiology and LV function; treatment protocols, including medical interventions and cardiac resynchronization therapy when indicated, must be tailored to the underlying disease substrate. 
The indications for and timing of surgery for treatment of MR have evolved considerably over the past several decades as both operative techniques and patient outcomes have improved., ${ }^{5,6}$ These trends are especially true for patients with severe, degenerative MR of a myxomatous nature for whom valve repair has become the preferred strategy whenever feasible. Isolated valve repair for this indication can now be accomplished through a variety of minimally invasive approaches, including with the use of robotic techniques in highly specialized surgical centers. Patients are interested in pursuing less invasive approaches in the hopes of reducing the burden of perioperative complications and discomfort, without compromising their chances for a successful and durable outcome. Expert mitral valve surgeons may employ several techniques to accomplish this task, including leaflet resection, neochordal construction, prosthetic ring or band insertion, and edge-to-edge leaflet approximation. Emerging transcatheter technologies have attempted to replicate 1 or more of these surgical principles, thus far with varying success in clinical and experimental settings. Perioperative mortality rates for selected, low-surgical-risk patients with severe degenerative MR are now $<1 \%$ in major referral centers where a successful repair can be accomplished in over $95 \%$ of patients with isolated posterior mitral leaflet pathology. Nevertheless, there remains concern that patients with severe, degenerative MR are not referred for surgical intervention in a timely fashion, even in referral centers of excellence. ${ }^{7}$ On the other end of the spectrum, symptomatic patients with functional MR that is due either to adverse LV remodeling after myocardial infarction or to a nonischemic cardiomyopathic process may benefit from surgical treatment to reduce or eliminate the excess LV volume load. A down-sized annuloplasty repair or chordal-sparing valve replacement is undertaken as dictated by the anatomic and hemodynamic features encountered in an individual patient. Many such patients are considered intermediateto-high risk for perioperative mortality or major complications. A less invasive approach, in combination with percutaneous coronary intervention for concomitant treatment of important coronary artery disease, may be of value in this setting. The use of transcatheter mitral valve repair in patients with functional MR appears to be both feasible and beneficial for selected patients. ${ }^{8}$ As these technologies become available for patients with either degenerative or functional MR, it will be important for experienced referral centers and cohesive heart teams to guide their deployment into clinical practice. As well, the short- and long-term efficacy, safety, comparative effectiveness and cost of these technologies must be evaluated through a dynamic registry supported by relevant stakeholders.

\section{CRITICAL COMPONENTS FOR SUCCESSFUL TRANSCATHETER MR THERAPIES}

\subsection{Heart Team}

The heart team approach, as utilized in the landmark SYNTAX (TAXUS Drug-Eluting Stent versus Coronary Artery Bypass Surgery for the Treatment of Narrowed Arteries; NCT00114972) ${ }^{9}$ and PARTNER (Placement of Aortic Transcatheter Valve; NCT00530894) ${ }^{1,2}$ trials, and embedded in the management of patients with advanced heart failure, is now an established paradigm for the care of patients with complex coronary or aortic valve disease. This approach was also followed in EVEREST (Endovascular Valve Edge-to-Edge Repair Study), which evaluated the efficacy and safety of the MitraClip. ${ }^{10-12}$

The key members of the heart team for transcatheter therapies for MR include primary (general) cardiologists, interventional cardiologists, cardiac surgeons, imaging specialists, valve and heart failure specialists, electrophysiologists, cardiac anesthesiologists, catheterization laboratory technologists, perfusionists, nurses, nurse practitioners, physician assistants, care coordinators, research coordinators, administrators, nutritionists, physical therapists, exercise physiologists, and social workers. At times, it will be appropriate to include a geriatric cardiologist or geriatrician, particularly when assessing frailty/comorbidities of the older adult; additional consultants may be required (nephrology, neurology, or oncology). A heart team leader is responsible for the coordination and integration of these several contributors.

\subsubsection{Role of the Primary Cardiologist}

The initial diagnosis and management of the patients with MR resides with the primary cardiologist whose clinical decision making is informed by echocardiographic imaging, other imaging, and exercise data as needed. He or she will determine the timing of referral for intervention and then work with the interventional cardiologist and cardiac surgeon to determine the best course of action based on an individualized risk/benefit analysis and an understanding of patient values and preferences. The primary cardiologist is often in the best position to communicate with the family throughout the care process and will provide longitudinal follow-up after the procedure, in coordination with the interventionalist and surgeon.

\subsubsection{Role of the Imaging Specialist(s)}

Accurate assessment of mitral valve anatomy and function requires a portfolio of imaging capabilities, including 2- and 3-dimensional transthoracic and transesophageal echocardiography and cardiac magnetic resonance imaging. Quantitative assessment of the severity of mitral 
valve disease using several imaging capabilities is essential before the procedure and at follow-up. Additional insights are to be gained through coronary angiography (either invasive or noninvasive) and delineation of the anatomic relationship between the coronary sinus and the mitral annulus. Standardized datasets should be collected and the American Society of Echocardiography definitions of severe $\mathrm{MR}^{11}$ should be incorporated in registry reporting. The need for other arterial or venous imaging will be driven by the specific mitral valve technology and its method of delivery. It is essential for the imaging specialist to be skilled in providing live imaging capabilities because they are often required to assist in the procedure.

\subsubsection{Role of the Heart Valve and Heart Failure Specialist}

Heart valve and heart failure specialists are important contributors to the heart team. The perspective of a heart failure specialist is particularly appropriate for the assessment and management of patients with MR and LV systolic dysfunction of any etiology.

\subsubsection{Role of the Interventional Cardiologist}

The interventional cardiologist will be skilled in all aspects of transcatheter structural and coronary heart disease procedures. He or she will work collaboratively with the other members of the heart team in the evaluation and procedural management of the patient, as well as with early post-procedural follow-up. Knowledge of mitral valve disease, imaging, hemodynamics, procedure specifics, adjunct medications, and complications is mandatory. Specific competencies will be addressed in a forthcoming multisocietal document.

\subsubsection{Role of the Cardiac Surgeon}

The cardiac surgeon will see patients in collaboration with the primary and interventional cardiologist and be competent in catheter-based and surgical approaches to MR, including repair and replacement options. Specific competencies will be addressed in a forthcoming multisocietal document. It is recognized that some surgeons have experience with and expertise in catheter-based techniques gained through TAVR procedures. The cardiac surgeon and interventional cardiologist will collaborate during the performance of transcatheter mitral procedures and will designate the primary and secondary operator as appropriate for the specific findings and challenges encountered in any individual patient.

\subsection{Specialized Facilities}

\subsubsection{Regional Heart Centers}

Many cardiac catheterization and cardiac surgical programs have a low volume of structural heart disease cases. In low-volume centers, for example, mitral valve replacement may be performed more frequently than appropriate for management of patients with degenerative MR for whom repair is strongly recommended. In addition, patient outcomes vary inversely as a function of operator and institutional volume. $^{12,13}$ The National Institutes for Health and Clinical Excellence in the United Kingdom have recommended volume criteria for mitral valve repair. ${ }^{14}$ The challenges of evaluating and managing patients with MR and significant comorbidities, such as heart failure, require multidisciplinary team care in a high-volume referral center with the infrastructure necessary to ensure best outcomes. The example established by the dissemination of TAVR should pertain to the release of therapies for MR. Accordingly, a detailed list of facilities and personnel experience, pre- and post-procedural care protocols, and complication management strategies must be developed and maintained. All data must be standardized and sent to a central registry for analysis and reporting. The level of commitment needed at the institutional level to establish and maintain the program cannot be overstated.

\subsubsection{Procedure Setting}

A cardiac catheterization laboratory with adequate space ( $\sim 800 \mathrm{sq} \mathrm{ft}$ ) to accommodate the operators, imagers, cardiac anesthesiologists, support staff, and their necessary equipment (including transesophageal echocardiography equipment, anesthesia machines, and intra-aortic balloon pumps) is mandatory. There must be high-quality, singleplane fluoroscopy and cineangiography. Other imaging modalities, such as computed tomography and magnetic resonance imaging with real-time 3-dimensional reconstruction, are expected to play an increasing role during the procedure. A hybrid operating suite is not strictly necessary for mitral procedures at this stage of development, but laminar air flow to provide operating room-level sterility is mandatory. Should a transcatheter mitral valve replacement option evolve, however, a hybrid suite with the capability for cardiopulmonary bypass would be needed. The equipment necessary to perform the procedure, including wires, sheaths, balloons, and devices of multiple sizes must be available. Support staff may include individuals with a predominant background and skill set in either interventional or surgical procedures, as dictated by patient- and procedural-specific needs. Procedural teams function best with both disciplines represented and working collaboratively.

It is anticipated that patients will be cared for in specialized cardiac or cardiac surgical intensive care units after the procedure, then transitioned to telemetry care as their hemodynamics, rhythm, respiratory status, and vascular access issues allow. It will be important for institutions to designate a single intensive care area for post-procedural care to optimize expertise, team training, and the development of care protocols. Expertise may require integration of cardiac and surgical nursing competencies. 


\section{LITERATURE REVIEW}

\subsection{Clinical Trials in the United States}

Approaches under investigation for transcatheter mitral valve repair or replacement include the edge-to-edge clip, off-pump adjustable neochordal implantation, indirect annuloplasty (generally via coronary sinus remodeling), cinching devices to induce annular reduction, external compression, direct annuloplasty (transcatheter surgical rings or sutures), energy-mediated annuloplasty (collagen shrinking), and transcatheter mitral valve replacement. Of the above technologies, the edge-to-edge MitraClip has undergone the most extensive human investigation thus far. ${ }^{15}$ This device is fashioned after a direct surgical method that relies on suture approximation of the leaflets to create a double orifice valve. ${ }^{16}$

The initial U.S. experience with transcatheter mitral valve repair for MR in 27 patients using the MitraClip was reported in the EVEREST phase I trial in 2005, ${ }^{17}$ with a subsequent expanded analysis in 2009 of 107 patients with at least 1-year follow-up. ${ }^{10}$ This initial experience was favorable in terms of acute procedural success, safety, and functional outcome, although $30 \%$ of patients required mitral valve surgery for treatment of 3 or $4+$ MR within 3.2 years of device implantation.

The pivotal EVEREST II trial (NCT00209274) randomized 279 patients with 3 or $4+$ chronic MR secondary to malcoaptation of the middle scallop of the anterior and posterior leaflets in a 2:1 ratio to transcatheter MitraClip repair versus open surgical repair. ${ }^{18}$ The primary efficacy endpoint at 12 months (composite of freedom from death, surgery for mitral valve dysfunction, and 3 or $4+\mathrm{MR}$ ) was reached in $57 \%$ of transcatheter MitraClip repair patients versus $73 \%$ of surgical patients $(P=.007)$. Mortality rates were similar between groups and the efficacy outcome difference was driven by a $20 \%$ incidence rate of surgery for mitral valve dysfunction in the MitraClip arm (vs $2 \%$ in the surgery arm, $P<.001)$. Although the rate of 3 or $4+\mathrm{MR}$ at 12 months was nearly identical for the groups $(21 \%$ transcatheter repair vs $20 \%$ surgery), in this intention-to-treat analysis, patients assigned to surgery, but who did not undergo surgery, were considered treatment failures. In a per-protocol analysis, freedom from death, mitral valve surgery for persistent MR, and the occurrence of 3 to $4+\mathrm{MR}$ at 12 months was $72 \%$ for the transcatheter arm compared with $88 \%$ for surgery $(P=.02)$. The incidence rates for 3 to $4+\mathrm{MR}$ at 1 year in this per-protocol analysis were $17 \%$ in the transcatheter therapy arm versus $4 \%$ in the surgery $\operatorname{arm}(P=.01)$. The primary safety outcome, a composite of major adverse events at 30 days, favored the transcatheter group (15\% transcatheter repair arm vs $48 \%$ surgery arm; $P<.001)$. The higher rate of major adverse events in the surgery arm at 30 days was driven largely by an excess hazard of transfusion of 2 or more units of blood $(13 \%$ transcatheter repair arm vs $45 \%$ surgery arm; $P<.01$ ). With open surgery, the incidence of major morbidity, as defined by the STS, was $9 \%$ versus $2 \%$ in the transcatheter $\operatorname{arm}(P=.02)$. At 4 years, overall mortality was similar between groups $(17 \%$ transcatheter arm vs $18 \%$ surgery; $P=$ .91) with mitral valve surgery or reoperation more often necessary following transcatheter repair $(25 \%$ transcatheter arm vs $5 \%$ surgery arm, $P<.001) .{ }^{19}$ Following transcatheter repair at 4 years, MR grade was 0 to $1+$ in $42 \%$ of patients, $2+$ in $37 \%$, and 3 to $4+$ in $21 \%$. Following surgical repair at 4 years, MR grade was 0 to $1+$ in $82 \%, 2+$ in $9 \%$, and 3 to $4+$ in $9 \%(P<.001)$.

Seventy-eight patients with 3 or $4+$ symptomatic MR for whom the predicted perioperative mortality rate was $\geq 12 \%$ were enrolled in the EVEREST II High Risk Study (HRS). ${ }^{20}$ Fifty-six percent of patients had functional MR, and $44 \%$ of patients had degenerative MR. A referent group of patients who were screened concurrently, but not enrolled, allowed for survival comparison with a group managed conservatively. In the treated group, the MitraClip reduced the severity of MR in a majority of patients and was associated with improved symptoms, LV reverse remodeling, recurrent heart failure hospitalizations, quality of life, and survival at 12 months. ${ }^{20}$ Implantation of the MitraClip was successful in $95 \%$ of 127 prohibitive-surgical-risk patients with degenerative MR treated between 2003 and 2012. ${ }^{21}$ One-year survival was $74 \%$ and was associated with similar improvements in functional status, quality of life, indices of LV remodeling, and recurrent hospitalizations for heart failure in this anatomic cohort.

Salutary effects included reduced MR grade, LV reverse remodeling, fewer rehospitalizations for heart failure, and improved quality of life. The COAPT (Clinical Outcomes Assessment of the MitraClip Percutaneous Therapy for High Surgical Risk Patients; NCT01626079) and RESHAPE-HF (Randomized Study of the MitraClip Device in Heart Failure Patients With Clinically Significant Functional Mitral Regurgitation; NCT01772108) trials have been designed to evaluate the MitraClip therapy in very high surgical risk patients with functional MR, reduced LV ejection fraction, and New York Heart Association functional class III or IV heart failure.

\subsection{European Registry and Observational Studies}

The MitraClip system received CE Mark approval in March 2008 and commercialization began in September 2008. The ACCESS-EU (ACCESS-Europe A Two Phase Observational Study of the MitraClip System in Europe) phase I study began enrolling patients in Europe in April 2009. Enrollment in ACCESS-EU phase I was completed on April 13, 2011, and 12-month clinical data collected as of June 15, 2012, were reported in September 2013. ${ }^{22}$ The implant success rate was $99.6 \%$ for 567 patients (EuroSCORE [European System for Cardiac Operative Risk 
Evaluation] $23 \pm 18 \%$ ) enrolled from 14 centers. Thirtyday and 1-year mortality rates were $3.4 \%$ and $19 \%$, respectively. By 1 year, open mitral valve surgery was necessary in $6.3 \%$ of patients, $3.4 \%$ of patients required a second MitraClip procedure to treat residual MR, and the incidence of 3 to $4+$ MR was $21 \%$. Among the 1-year survivors, $71 \%$ were in New York Heart Association functional class I or II with improvements in 6-min walk test and quality of life scores. With functional valve disease, MR grade at 1 year was 3 to $4+$ in $21 \%, 2+$ in $47 \%$, and 0 to $1+$ in $32 \%$ of patients. With degenerative valve disease, MR grade at 1 year was 3 to $4+$ in $25 \%, 2+$ in $42 \%$, and 0 to $1+$ in $33 \%$ of patients. In this post-approval European experience, MitraClip therapy was most frequently applied to high-risk, elderly patients, mainly with functional MR. Several other European observational studies in patients with both degenerative and functional MR, including high-surgical-risk patients, have been reported with directionally similar results. ${ }^{23-28}$ Investigators have cautioned that pre-assessment, treatment, and post-procedural care by an interdisciplinary team are essential to maximize clinical success, especially in high-surgical-risk patients. The 2012 European Society of Cardiology Guidelines on the Management of Valvular Heart Disease state that MitraClip may be considered for patients with life expectancy $>1$ year and symptomatic severe, secondary (functional) MR despite optimal medical therapy (including cardiac resynchronization therapy when indicated) who are deemed high risk or inoperable by a formal heart team (Class IIb, Level of Evidence: C). ${ }^{6}$ Surgical repair after failed MitraClip deployment is feasible, although more extensive valve scarring after clip implantation may necessitate valve replacement. ${ }^{29}$ Thirty-seven of 178 MitraClip patients in EVEREST II underwent open mitral valve surgery within 12 months of implant. Valve repair was possible in 20 patients, and valve replacement was required in 17 patients. Removal of the MitraClip was more difficult after 30 days because of fibrosis and scarring of the leaflets. Anterior leaflet pathology was a predictor of the need for valve replacement. ${ }^{30}$

\subsection{Other Transcatheter Mitral Valve Technologies}

Transcatheter mitral annuloplasty via the coronary sinus has been assessed in the CARILLON AMADEUS (Mitral Annuloplasty Device European Union) ${ }^{31}$ and TITAN (Transcatheter Implantation of Carillon Mitral Annulplasty Device $^{32}$ trials using the CARILLON Mitral Contour System (Cardiac Dimensions, Kirkland, Washington), and in studies using an alternative device (PTOLEMY [Safety and Efficacy of the Percutaneous Transvenous Mitral Annuloplasty (PTMA) Device]; NCT00568230). ${ }^{33}$ Recruitment in a subsequent evaluation of the PTMA device (PTOLEMY2Canada [Safety and Efficacy Study of the PTMA Device to Reduce Mitral Valve Regurgitation in Patients
With Heart Failure]; NCT00815386) ${ }^{34}$ was suspended once the device manufacturer ceased operations in 2011. Technical and anatomic challenges have thus far impeded application of coronary sinus annuloplasty devices although a potential adjunct role for their use in selected patients may emerge. Transapical beating heart mitral valve repair with deployment of neochordae has been reported. ${ }^{35}$ Human experience with other transcatheter devices, such as a septal sinus shortening system, has been extremely limited to date. $^{36}$

\section{OPERATOR TRAINING}

It is incumbent on professional societies to set minimal performance standards for these procedures rather than to defer to commercial sponsors. The societies should develop the curriculum, establish the metrics for evaluation, and certify completion of a training module. Challenges to this paradigm include access to a required minimum of cases, the appropriate balance of simulation and/or large animal laboratory experience, the limited number of centers at which these procedures have been performed to date, the limited number of senior mentors, and the disadvantages faced by operators and surgeons who have graduated from training programs and are now in practice. Our societies have outlined the specifics of a training curriculum in interventional fellowships for structural and adult congenital heart disease. ${ }^{37}$ Unanswered questions concern the duration of training, funding, team-based training needs, and the expectations for interventionalists and surgeons. The establishment of such training criteria, procedural volumes, and performance and evaluation metrics are beyond the scope of the document and will be addressed in the forthcoming SCAI/AATS/ACC/STS Multisocietal Consensus Statement: Operator and Institutional Requirements for Transcatheter Valve Repair and Replacement: Part 3: Mitral Valve. $^{38}$

\section{PROTOCOLS FOR CARE}

Specific protocols for pre-, intra-, and post-procedural patient assessment and care should be in place with clear delineation of the roles of the individual heart team members and establishment of a collaborative process for shared decision making with the patient. Protocols should involve assessment of mitral valve anatomy and function, cardiac chamber sizes, biventricular function, pulmonary artery pressures, and any concomitant aortic or tricuspid valve pathology. Knowledge of the coronary anatomy will be required. A complete assessment of medical comorbidities is a key component of this process. The need for other procedures (such as coronary revascularization) that may be indicated to achieve an optimal result should be identified. All patients referred for consideration of transcatheter therapy for MR should proceed down the same evaluation and treatment pathway so as to promote consistency, reduce 
variability, and allow for more uniform reporting of results. The process should help prevent inappropriate use of the technology, as well as post hoc misinterpretation of the data needed for optimal device utilization. Provision of longer-term follow-up care must be specified and protocols for surveillance imaging established.

\section{ASSESSMENT OF OUTCOMES}

Clinical, procedural, device, and administrative data collection, analysis, and reporting are vital aspects of the process whereby the utility and safety of any new technology can be established. The value of robust patient registries has been demonstrated most convincingly by the STS National Database and the ACC National Cardiovascular Data Registry (NCDR). In the ASCERT (ACCF/STS Collaboration on the Effectiveness of Revascularization Strategies) study, these 2 databases were conjoined and then linked to the Social Security Death Master File and the Centers for Medicare $\&$ Medicaid Services (CMS) Medicare Provider and Analysis Review repositories to inform outcomes analysis and comparative effectiveness research on real-world patients undergoing coronary revascularization. ${ }^{39}$ A novel, national clinical registry program for new transcatheter valve therapy (TVT) devices was created in December 2011 following Food and Drug Administration (FDA) approval of the Sapien Transcatheter Aortic Valve. ${ }^{40}$ The TVT registry (NCT01737528), a joint initiative of the STS and ACC, was developed in close collaboration with the FDA, CMS, and the Duke Clinical Research Institute. ${ }^{41}$ Its purpose is to provide an objective, comprehensive, and scientifically based resource to improve the quality of patient care, monitor the safety and effectiveness of novel transcatheter valve technologies, serve as a platform for TVT research, and enhance communication among multiple stakeholders. It is linked to other national and international registries to facilitate its mission. Importantly, the TVT registry fulfills the CMS National Coverage Determination (NCD) (May 2012) requirement for national registry participation for all TAVR centers. The registry enables device and procedure surveillance, quality improvement, and the performance of device labeling studies to speed access to new devices and support expansion of labeling with evidence development. The first TVT registry-embedded post-approval study was developed in partnership with the FDA and Edwards Lifesciences, the industry sponsor of the first FDA-approved transcatheter aortic valve. Several more are now under discussion and in early development. The first embedded investigational new device study undertaken through the registry and sponsored by STS and ACC, with the approval of FDA and CMS, led in a short time to expanded indications for TAVR. ${ }^{42}$ The addition of transcatheter MR therapies and other heart valve lesions is a logical and necessary extension of the TVT registry. The process to incorporate mitral technologies has already begun, with careful delineation of the critical data elements that must be captured in a standardized and well-defined manner with seamless linkage to other databases and harmonization with pivotal clinical trials to inform regulatory approval, promote best practices, and ensure high-quality patient-centered care. It is anticipated that participating centers will collect information regarding patient demographics, comorbidities, functional status, patient-reported quality of life, hemodynamics, procedural details, and post-procedure 30-day and 1-year outcomes.

\section{SUMMARY AND RECOMMENDATIONS}

Transcatheter therapies hold promise for the management of carefully selected patients with severe MR using less invasive means whereby the experience of care may be improved. Although registry experience in the United States and Europe has been encouraging, only a single randomized trial using a specific device in patients with MR has been reported with recent FDA approval for use of this device in eligible U.S. patients with degenerative MR. Further research involving a wider spectrum of patients and devices is strongly encouraged. It is recognized that the intricate structure and complex function of the mitral apparatus pose challenging technical hurdles. It is imperative that professional societies, industry, payers, and regulatory agencies work collaboratively to promote needed research and ensure that the technology is disseminated rationally and responsibly in the best interests of patients. The following recommendations for a path forward closely mirror those enunciated in a previous ACCF/STS Societal Overview. The leadership of our organizations proposes:

1. Continued development of regional heart valve referral centers of excellence. Criteria for the performance of transcatheter therapy for MR in such centers should be established and refined. Availability of new devices and reimbursement for their application should be limited to those centers that meet national criteria.

2. A heart valve referral center of excellence is defined in part by the competence and experience of the individual members of a dedicated, multidisciplinary heart team, each of whom has a clearly defined role and works collaboratively in the best interest of patients. Input is required from general cardiologists, heart valve and heart failure experts, advanced imagers, interventionalists, cardiac surgeons, and allied members of the heart team (eg, anesthesia, geriatrics, neurology, nephrology, nursing, care coordination, pharmacy, physical therapy, and social work). All aspects of patient evaluation and care must be addressed, including late follow-up. Lack of dedicated care pathways should disqualify a center from participation.

3. All centers are required to participate in an ongoing TVT registry to benchmark quality and enable outcomes and cost analysis, as well as comparative effectiveness research. 
Data quality, as well as productivity in publication of research projects from the registry, should be monitored.

4. Operator training and credentialing criteria for mitral valve procedures must be established and are the subject of a joint professional competency document in development.

5. Guidelines for transcatheter mitral valve interventions should be substantiated and developed. Performance measures and appropriate use criteria would follow. Presently, the MitraClip is approved only for prohibitive surgical risk patients with degenerative MR who meet anatomic eligibility criteria. The COAPT trial (NCT01626079) will address the role of the MitraClip device in high surgical risk patients with functional MR.

The ACC, AATS, SCAI, and STS are committed to the principle of working collaboratively together as professional societies and in partnership with the FDA, CMS, and industry partners to bring promising, innovative mitral valve technologies into clinical practice as validated by the evidence and in the best interests of patients.

\section{PRESIDENT AND STAFF LIST}

\section{American College of Cardiology}

John Gordon Harold, MD, MACC, President

Shalom Jacobovitz, Chief Executive Officer

William J. Oetgen, MD, FACC, Senior Vice President,

Science, Education and Quality

Charlene L. May, Senior Director, Science and Clinical Policy

Dawn R. Phoubandith, MSW, Director, ACC Clinical

Documents

Eva Marie Grace, Specialist, ACC Clinical Committees

\section{The American Association for Thoracic Surgery \\ David J. Sugarbaker, MD, President \\ Cindy VerColen, Executive Director}

\section{Society for Cardiovascular Angiography and Interventions Foundation}

Theodore A. Bass, MD, FACC, FSCAI, President

Norm Linsky, Executive Director

\section{The Society of Thoracic Surgeons}

Douglas E. Wood, MD, President

Robert A. Wynbrandt, Executive Director \& General Counsel

\section{References}

1. Leon MB, Smith CR, Mack M, et al. Transcatheter aortic-valve implantation for aortic stenosis in patients who cannot undergo surgery. $N$ Engl J Med. 2010;363: 1597-607.

2. Smith CR, Leon MB, Mack MJ, et al. Transcatheter versus surgical aortic-valve replacement in high-risk patients. $N$ Engl J Med. 2011;364:2187-98.

3. Holmes DR Jr, Mack MJ. Transcatheter valve therapy: a professional society overview from the American College of Cardiology Foundation and the Society of Thoracic Surgeons. J Am Coll Cardiol. 2011;58:445-55.
4. Nkomo VT, Gardin JM, Skelton TN, et al. Burden of valvular heart diseases: a population-based study. Lancet. 2006;368:1005-11.

5. Bonow RO, Carabello BA, Chatterjee K, et al. ACC/AHA 2006 guidelines for the management of patients with valvular heart disease: a report of the American College of Cardiology/American Heart Association Task Force on Practice Guidelines (Writing Committee to Revise the 1998 Guidelines for the Management of Patients With Valvular Heart Disease). J Am Coll Cardiol. 2006;48:e1-148.

6. Vahanian A, Alfieri O, Andreotti F, et al. Guidelines on the management of valvular heart disease (version 2012). Eur Heart J. 2012;33:2451-96.

7. Bach DS, Awais M, Gurm HS, et al. Failure of guideline adherence for intervention in patients with severe mitral regurgitation. J Am Coll Cardiol. 2009;54: 860-5.

8. Rogers JH, Franzen O. Percutaneous edge-to-edge MitraClip therapy in the management of mitral regurgitation. Eur Heart J. 2011;32:2350-7.

9. Serruys PW, Morice MC, Kappetein AP, et al. Percutaneous coronary intervention versus coronary-artery bypass grafting for severe coronary artery disease. N Engl J Med. 2009;360:961-72.

10. Feldman T, Kar S, Rinaldi M, et al. Percutaneous mitral repair with the MitraClip system: safety and midterm durability in the initial EVEREST (Endovascular Valve Edge-to-Edge Repair Study) cohort. J Am Coll Cardiol. 2009;54: 686-94.

11. Zoghbi WA, Enriquez-Sarano M, Foster E, et al. Recommendations for evaluation of the severity of native valvular regurgitation with two-dimensional and Doppler echocardiography. J Am Soc Echocardiogr. 2003;16:777-802.

12. Bolling SF, Li S, O'Brien SM, et al. Predictors of mitral valve repair: clinical and surgeon factors. Ann Thorac Surg. 2010;90:1904-11.

13. Birkmeyer JD, Stukel TA, Siewers AE, et al. Surgeon volume and operative mortality in the United States. N Engl J Med. 2003;349:2117-27.

14. Bridgewater B, Hooper T, Munsch C, et al. Mitral repair best practice: proposed standards. Heart. 2006;92:939-44.

15. Munkholm-Larsen S, Wan B, Tian DH, et al. A systematic review on the safety and efficacy of percutaneous edge-to-edge mitral valve repair with the MitraClip system for high surgical risk candidates. Heart. June 27, 2013 [E-pub ahead of print].

16. Alfieri O, Maisano F, De Bonis M, et al. The double-orifice technique in mitral valve repair: a simple solution for complex problems. J Thorac Cardiovasc Surg. 2001;122:674-81.

17. Feldman T, Wasserman HS, Herrmann HC, et al. Percutaneous mitral valve repair using the edge-to-edge technique: six-month results of the EVEREST phase I clinical trial. J Am Coll Cardiol. 2005;46:2134-40.

18. Feldman T, Foster E, Glower DD, et al. Percutaneous repair or surgery for mitral regurgitation. N Engl J Med. 2011;364:1395-406.

19. Mauri L, Foster E, Glower DD, et al. 4-year results of a randomized controlled trial of percutaneous repair versus surgery for mitral regurgitation. J Am Coll Cardiol. 2013;62:317-28.

20. Whitlow PL, Feldman T, Pedersen WR, et al. Acute and 12-month results with catheter-based mitral valve leaflet repair: the EVEREST II (Endovascular Valve Edge-to-Edge Repair) High Risk Study. J Am Coll Cardiol. 2012;59:130-9.

21. Lim DS, Reynolds MR, Feldman T, et al. Improved functional status and quality of life in prohibitive surgical risk patients with degenerative mitral regurgitation following transcatheter mitral valve repair with the MitraClip(R) system. J Am Coll Cardiol. October 24, 2013 [E-pub ahead of print].

22. Maisano F, Franzen O, Baldus S, et al. Percutaneous mitral valve interventions in the real world: early and 1-year results from the ACCESS-EU, a prospective, multicenter, nonrandomized post-approval study of the MitraClip therapy in Europe. J Am Coll Cardiol. 2013;62:1052-61.

23. Baldus S, Schillinger W, Franzen O, et al. MitraClip therapy in daily clinical practice: initial results from the German Transcatheter Mitral Valve Interventions (TRAMI) registry. Eur J Heart Fail. 2012;14:1050-5.

24. Surder D, Pedrazzini G, Gaemperli O, et al. Predictors for efficacy of percutaneous mitral valve repair using the MitraClip system: the results of the MitraSwiss registry. Heart. 2013;99:1034-40.

25. Grasso C, Capodanno D, Scandura S, et al. One- and twelve-month safety and efficacy outcomes of patients undergoing edge-to-edge percutaneous mitral valve repair (from the GRASP Registry). Am J Cardiol. 2013;111:1482-7.

26. Taramasso M, Denti P, Buzzatti N, et al. Mitraclip therapy and surgical mitral repair in patients with moderate to severe left ventricular failure causing functional mitral regurgitation: a single-centre experience. Eur J Cardiothorac Surg. 2012;42:920-6.

27. Armoiry X, Brochet E, Lefevre T, et al. Initial French experience of percutaneous mitral valve repair with the MitraClip: a multicentre national registry. Arch Cardiovasc Dis. 2013;106:287-94. 
28. Conradi L, Treede H, Rudolph V, et al. Surgical or percutaneous mitral valve repair for secondary mitral regurgitation: comparison of patient characteristics and clinical outcomes. Eur J Cardiothorac Surg. 2013;44:490-6.

29. Geidel S, Schmoeckel M. Impact of failed mitral clipping on subsequent mitral valve operations. Ann Thorac Surg. September 25, 2013 [E-pub ahead of print].

30. Glower D, Ailawadi G, Argenziano M, et al. EVEREST II randomized clinical trial: predictors of mitral valve replacement in de novo surgery or after the MitraClip procedure. J Thorac Cardiovasc Surg. 2012;143:S60-3.

31. Schofer J, Siminiak T, Haude M, et al. Percutaneous mitral annuloplasty for functional mitral regurgitation: results of the CARILLON Mitral Annuloplasty Device European Union Study. Circulation. 2009;120:326-33.

32. Siminiak T, Wu JC, Haude M, et al. Treatment of functional mitral regurgitation by percutaneous annuloplasty: results of the TITAN trial. Eur J Heart Fail. 2012; 14:931-8.

33. Sack S, Kahlert P, Bilodeau L, et al. Percutaneous transvenous mitral annuloplasty: initial human experience with a novel coronary sinus implant device, Circ Cardiovasc Interv. 2009;2:277-84.

34. Machaalany J, Bilodeau L, Hoffmann R, et al. Treatment of functional mitral valve regurgitation with the permanent percutaneous transvenous mitral annuloplasty system: results of the multicenter international Percutaneous Transvenous Mitral Annuloplasty System to Reduce Mitral Valve Regurgitation in Patients with Heart Failure trial. Am Heart J. 2013;165:761-9.
35. Seeburger J, Borger MA, Tschernich H, et al. Transapical beating heart mitra valve repair. Circ Cardiovasc Interv. 2010;3:611-2.

36. Masson JB, Webb JG. Percutaneous treatment of mitral regurgitation. Circ Cardiovasc Interv. 2009;2:140-6.

37. Ruiz CE, Feldman TE, Hijazi ZM, et al. Interventional fellowship in structural and congenital heart disease for adults. J Am Coll Cardiol Intv. 2010;3: e1- 15 .

38. Tommaso CL, et al. SCAI/AATS/ACCF/STS multisocietal consensus statement: operator and institutional requirements for transcatheter valve repair and replacement, part 3: mitral valve. J Am Coll Cardiol. 2014. In press.

39. Weintraub WS, Grau-Sepulveda MV, Weiss JM, et al. Comparative effectiveness of revascularization strategies. N Engl J Med. 2012;366:1467-76.

40. STS/ACC TVT Registry: An Initiative of the STS National Database and the ACC's NCDR. Available at: https://www.ncdr.com/TVT/Home/Default.aspx. Accessed October 23, 2013.

41. Carroll JD, Edwards FH, Marinac-Dabic D, et al. The STS-ACC transcatheter valve therapy national registry: a new partnership and infrastructure for the introduction and surveillance of medical devices and therapies. J Am Coll Cardiol. 2013;62:1026-34.

42. FDA News Release. FDA Approval Expands Access to Artificial Heart Valve for Inoperable Patients. September 23, 2013. Available at: http:// www.fda.gov/NewsEvents/Newsroom/PressAnnouncements/ucm369510.htm. Accessed October 23, 2013.

APPENDIX 1. Author relationships with industry and other entities (relevant)—transcatheter therapies for mitral regurgitation: A professional society overview from the ACC, AATS, SCAI, and STS

\begin{tabular}{|c|c|c|c|c|c|c|c|}
\hline Committee member & Employment & Consultant & $\begin{array}{c}\text { Speaker's } \\
\text { bureau }\end{array}$ & $\begin{array}{l}\text { Ownership/ } \\
\text { partnership/ } \\
\text { principal }\end{array}$ & $\begin{array}{l}\text { Personal } \\
\text { research }\end{array}$ & $\begin{array}{c}\text { Institutional, } \\
\text { organizational, or } \\
\text { other financial benefit }\end{array}$ & $\begin{array}{r}\text { Expert } \\
\text { witness } \\
\end{array}$ \\
\hline $\begin{array}{l}\text { Patrick T. O'Gara, } \\
\text { Co-Chair }\end{array}$ & $\begin{array}{l}\text { Brigham and Women's } \\
\text { Hospital-Professor of } \\
\text { Medicine; Harvard Medical } \\
\text { School_Director, Clinical } \\
\text { Cardiology }\end{array}$ & None & None & None & None & None & None \\
\hline $\begin{array}{l}\text { John H. Calhoon, } \\
\text { Co-Chair }\end{array}$ & $\begin{array}{l}\text { University of Texas Health } \\
\text { Science Center-Professor } \\
\text { and Chair, CT Surgery } \\
\text { Department }\end{array}$ & None & None & None & None & None & None \\
\hline Marc R. Moon & $\begin{array}{l}\text { Barnes-Jewish Hospital, } \\
\text { Cardiothoracic Surgery, } \\
\text { Washington Medical } \\
\text { Center-Program Director, } \\
\text { Professor of Surgery }\end{array}$ & None & None & None & None & None & None \\
\hline Carl L. Tommaso & $\begin{array}{l}\text { NorthShore University } \\
\text { HealthSystem, Evanston } \\
\text { Hospital-Interventional } \\
\text { Cardiologist }\end{array}$ & None & None & None & None & None & None \\
\hline
\end{tabular}

This table represents the relationships of committee members with industry and other entities that were determined to be relevant to this document. These relationships were reviewed and updated in conjunction with all meetings and/or conference calls of the writing committee during the document development process. The table does not necessarily reflect relationships with industry at the time of publication. A person is deemed to have a significant interest in a business if the interest represents ownership of $\geq 5 \%$ of the voting stock or share of the business entity, or ownership of $\geq \$ 10,000$ of the fair market value of the business entity; or if funds received by the person from the business entity exceed $5 \%$ of the person's gross income for the previous year. Relationships that exist with no financial benefit are also included for the purpose of transparency. Relationships in this table are modest unless otherwise noted. Please refer to http://www.cardiosource.org/Science-And-Quality/Practice-Guidelines-and-Quality-Standards/Relationships-With-IndustryPolicy.aspx for definitions of disclosure categories or additional information about the ACC Disclosure Policy for Writing Committees. According to the ACC, a person has a relevant relationship IF: (a) The relationship or interest relates to the same or similar subject matter, intellectual property or asset, topic, or issue addressed in the document; or (b) The company/entity (with whom the relationship exists) makes a drug, drug class, or device addressed in the document, or makes a competing drug or device addressed in the document; or (c) The person or a member of the person's household, has a reasonable potential for financial, professional, or other personal gain or loss as a result of the issues/ content addressed in the document. 
APPENDIX 2. Peer reviewer relationships with industry and other entities (relevant)-transcatheter therapies for mitral regurgitation: A professional society overview from the ACC, AATS, SCAI, and STS

\begin{tabular}{|c|c|c|c|c|c|c|c|c|}
\hline Peer reviewer & Representation & Employment & Consultant & $\begin{array}{c}\text { Speaker's } \\
\text { bureau }\end{array}$ & $\begin{array}{c}\text { Ownership/ } \\
\text { partnership/ } \\
\text { principal }\end{array}$ & Personal research & $\begin{array}{c}\text { Institutional, } \\
\text { organizational, or } \\
\text { other financial benefit }\end{array}$ & $\begin{array}{l}\text { Expert } \\
\text { witness }\end{array}$ \\
\hline Steven R. Bailey & $\begin{array}{l}\text { Official Reviewer- } \\
\text { SCAI }\end{array}$ & $\begin{array}{l}\text { University of Texas } \\
\text { Medical Center- } \\
\text { Professor of Medicine } \\
\text { and Radiology }\end{array}$ & None & None & - Biostar & $\begin{array}{l}\text { - Boston Scientific } \\
\text { (DSMB) }\end{array}$ & None & None \\
\hline Deepak L. Bhatt & $\begin{array}{l}\text { Official Reviewer- } \\
\text { ACC Task Force on } \\
\text { Clinical Expert } \\
\text { Consensus } \\
\text { Documents }\end{array}$ & $\begin{array}{l}\text { VA Boston Healthcare } \\
\text { System-Chief, } \\
\text { Division of } \\
\text { Cardiology }\end{array}$ & None & None & None & $\begin{array}{l}\text { - Ethicon* } \\
\text { - Medtronic* }\end{array}$ & None & None \\
\hline James A. Burke & $\begin{array}{l}\text { Content Reviewer- } \\
\text { ACC Interventional } \\
\text { Section Leadership } \\
\text { Council }\end{array}$ & $\begin{array}{l}\text { Lehigh Valley Heart } \\
\text { Specialists- } \\
\text { Associate Chief of } \\
\text { Cardiology }\end{array}$ & None & None & None & None & None & None \\
\hline Joaquin E. Cigarroa & $\begin{array}{l}\text { Content Reviewer- } \\
\text { ACC Interventional } \\
\text { Section Leadership } \\
\text { Council }\end{array}$ & $\begin{array}{l}\text { Oregon Health \& } \\
\text { Science University, } \\
\text { Knight } \\
\text { Cardiovascular } \\
\text { Institute-Clinical } \\
\text { Professor of Medicine }\end{array}$ & None & None & None & None & None & None \\
\hline Marco A. Costa & $\begin{array}{l}\text { Content Reviewer- } \\
\text { ACC Interventional } \\
\text { Section Leadership } \\
\text { Council }\end{array}$ & $\begin{array}{l}\text { University Hospitals } \\
\text { Case Medical Center, } \\
\text { Interventional } \\
\text { Cardiovascular } \\
\text { Center-Director }\end{array}$ & $\begin{array}{l}\text { - Abbott Vascular* } \\
\text { - Boston Scientific } \\
\text { - Edwards Lifesciences } \\
\text { - Medtronic } \\
\text { - St. Jude Medical }\end{array}$ & None & None & - St. Jude Medical & $\begin{array}{l}\text { - Abbott Vascular* } \\
\text { - Boston Scientific* } \\
\text { - Lutonics* } \\
\text { - Medtronic* } \\
\text { - St. Jude Medical }\end{array}$ & None \\
\hline Abe DeAnda, Jr & $\begin{array}{l}\text { Official Reviewer- } \\
\text { AATS }\end{array}$ & $\begin{array}{l}\text { New York University- } \\
\text { Langone Medical } \\
\text { Center-Associate } \\
\text { Professor, } \\
\text { Cardiothoracic } \\
\text { Surgery }\end{array}$ & None & None & None & $\begin{array}{l}\text { - Cook, Inc. } \dagger \\
\text { - Edwards Bioscience } \dagger \\
\text { - Ethicon } \dagger\end{array}$ & None & None \\
\hline Linda D. Gillam & $\begin{array}{l}\text { Content Reviewer- } \\
\text { ACC Cardiovascular } \\
\text { Imaging Section } \\
\text { Leadership Council }\end{array}$ & $\begin{array}{l}\text { Morristown Medical } \\
\text { Center-Professor of } \\
\text { Cardiology; Vice } \\
\text { Chair, Cardiovascular } \\
\text { Medicine }\end{array}$ & None & None & None & $\begin{array}{l}\text { - Edwards } \\
\text { Lifesciences } \dagger\end{array}$ & $\begin{array}{l}\text { - Edwards } \\
\text { Lifesciences } \dagger\end{array}$ & None \\
\hline
\end{tabular}




\begin{tabular}{|c|c|c|c|c|c|c|c|c|}
\hline Ziyad M. Hijazi & $\begin{array}{l}\text { Official Reviewer- } \\
\text { SCAI }\end{array}$ & $\begin{array}{l}\text { Rush University } \\
\text { Medical Center- } \\
\text { Professor of } \\
\text { Pediatrics and } \\
\text { Internal Medicine; } \\
\text { Rush Center for } \\
\text { Congenital and } \\
\text { Structural Heart } \\
\text { Disease-Director }\end{array}$ & - Occlutech* & None & - Colibri Heart Valve $\dagger$ & None & None & None \\
\hline David R. Holmes, Jr & $\begin{array}{l}\text { Official Reviewer- } \\
\text { ACC BOT and } \\
\text { Content Reviewer- } \\
\text { NCDR TVT Registry } \\
\text { Steering Committee }\end{array}$ & $\begin{array}{l}\text { Mayo Clinic_- } \\
\text { Consultant, } \\
\text { Cardiovascular } \\
\text { Diseases }\end{array}$ & None & None & None & None & - Atritech $\dagger$ & None \\
\hline Saibal Kar & $\begin{array}{l}\text { Content Reviewer- } \\
\text { ACC Interventional } \\
\text { Section Leadership } \\
\text { Council }\end{array}$ & $\begin{array}{l}\text { Cedars-Sinai Medical } \\
\text { Center, Division of } \\
\text { Cardiology }\end{array}$ & $\begin{array}{l}\text { - Abbott Vascular* } \\
\text { - AGA Medical }\end{array}$ & - Medtronic & None & $\begin{array}{l}\text { - Abbott Vascular* } \\
\text { - Biosensor } \\
\text { International* } \\
\text { - Boston Scientific* } \\
\text { - St. Jude Medical* }\end{array}$ & None & None \\
\hline James B. McClurken & $\begin{array}{l}\text { Content Reviewer- } \\
\text { ACC Surgeons } \\
\text { Section Leadership } \\
\text { Council }\end{array}$ & $\begin{array}{l}\text { Doylestown Hospital- } \\
\text { Director of Thoracic } \\
\text { Surgery, R A Reif } \\
\text { Heart Institute; } \\
\text { Temple University } \\
\text { Hospital_-Professor } \\
\text { of Surgery } \\
\text { (Cardiothoracic) } \\
\text { Emeritus }\end{array}$ & None & None & None & None & None & None \\
\hline D. Craig Miller & Official Reviewer-STS & $\begin{array}{l}\text { Stanford University } \\
\text { Medical Center } \\
\text { Cardiothoracic } \\
\text { Surgery Clinic- } \\
\text { Professor of } \\
\text { Cardiovascular } \\
\text { Surgery }\end{array}$ & $\begin{array}{l}\text { - Abbott Vascular } \\
\text { - Edwards } \\
\text { Lifesciences } \dagger \\
\text { - Medtronic* } \\
\text { - St. Jude Medical }\end{array}$ & None & None & $\begin{array}{l}\text { - Edwards } \\
\text { Lifesciences } \dagger\end{array}$ & None & None \\
\hline
\end{tabular}




\begin{tabular}{|c|c|c|c|c|c|c|c|c|}
\hline Peer reviewer & Representation & Employment & Consultant & $\begin{array}{c}\text { Speaker's } \\
\text { bureau }\end{array}$ & $\begin{array}{c}\text { Ownership/ } \\
\text { partnership/ } \\
\text { principal }\end{array}$ & Personal research & $\begin{array}{c}\text { Institutional, } \\
\text { organizational, or } \\
\text { other financial benefit }\end{array}$ & $\begin{array}{l}\text { Expert } \\
\text { witness }\end{array}$ \\
\hline Hani K. Najm & $\begin{array}{l}\text { Content Reviewer- } \\
\text { ACC Surgeons } \\
\text { Section Leadership } \\
\text { Council }\end{array}$ & $\begin{array}{l}\text { National Guard Health } \\
\text { Affairs-Deputy } \\
\text { Chairman and Head, } \\
\text { Cardiac Surgery }\end{array}$ & None & None & None & None & None & None \\
\hline Stephen R. Ramee & $\begin{array}{l}\text { Content Reviewer- } \\
\text { ACC Interventional } \\
\text { Section Leadership } \\
\text { Council }\end{array}$ & $\begin{array}{l}\text { Ochsner Clinic } \\
\text { Foundation- } \\
\text { Director, Cardiac } \\
\text { Catheterization }\end{array}$ & None & None & $\begin{array}{l}\text { - Access Closure* } \\
\text { - Boston Scientific* }\end{array}$ & $\begin{array}{l}\text { - } \text { Abbott } \dagger \\
\text { - Boston Scientific } \dagger \\
\text { - Edwards } \\
\text { Lifesciences } \dagger \\
\text { - Medtronic } \dagger\end{array}$ & None & None \\
\hline Pasala S. Ravichandran & $\begin{array}{l}\text { Content Reviewer- } \\
\text { ACC Surgeons } \\
\text { Section Leadership } \\
\text { Council }\end{array}$ & $\begin{array}{l}\text { Oregon Health \& } \\
\text { Science University- } \\
\text { Associate Professor }\end{array}$ & None & None & None & None & None & None \\
\hline Vinod H. Thourani & $\begin{array}{l}\text { Official Reviewer- } \\
\text { AATS }\end{array}$ & Emory University & $\begin{array}{l}\text { - Edwards Lifesciences } \\
\text { - Sorin } \\
\text { - St. Jude Medical }\end{array}$ & None & $\begin{array}{l}\text { - Apica } \\
\text { Cardiovascular } \dagger\end{array}$ & - Maquet & None & None \\
\hline Edward R. Tuohy, IV & $\begin{array}{l}\text { Official Reviewer- } \\
\text { ACC Board of } \\
\text { Governors }\end{array}$ & $\begin{array}{l}\text { Cardiac Specialists- } \\
\text { Interventional } \\
\text { Cardiologist; Yale- } \\
\text { New Haven Health } \\
\text { System-- } \\
\text { Interventional } \\
\text { Cardiologist }\end{array}$ & None & None & None & None & None & None \\
\hline James S. Tweddell & $\begin{array}{l}\text { Content Reviewer- } \\
\text { ACC Adult } \\
\text { Congenital and } \\
\text { Pediatric Cardiology } \\
\text { Section Leadership } \\
\text { Council }\end{array}$ & $\begin{array}{l}\text { Children's Hospital of } \\
\text { Wisconsin-The S. } \\
\text { Bert Litwin Chair, } \\
\text { Cardiothoracic } \\
\text { Surgery; Medical } \\
\text { College of } \\
\text { Wisconsin- } \\
\text { Professor of Surgery } \\
\text { and Pediatrics; Chair, } \\
\text { Division of } \\
\text { Cardiothoracic } \\
\text { Surgery }\end{array}$ & None & None & None & None & None & None \\
\hline
\end{tabular}


Pediatric Cardiology Pediatrics;

Section Leadership Children's Healthcare of

Council

Atlanta-Director,

Cardiac

\section{Catheterization}

Laboratories

This table represents the relationships of reviewers with industry and other entities that were disclosed at the time of peer review. It does not necessarily reflect relationships with industry at the time of publication. A person is deemed

have a significant interest in a business if the interest represents ownership of $\geq 5 \%$ of the voting stock or share of the business entity, or ownership of $\geq \$ 10,000$ of the fair market value of the business entity; or if funds received by he person from the business entity exceed $5 \%$ of the person's gross income for the previous year. A relationship is considered to be modest if it is less than significant under the preceding definition. Relationships that exist with no fnancial benefit are also included for the purpose of transparency. Relationships in this table are modest unless otherwise noted. Names are listed in alphabetical order within each category of review. According to the ACC, a person has a relevant relationship IF: (a) The relationship or interest relates to the same or similar subject matter, intellectual property or asset, topic, or issue addressed in the document; or (b) The company/entity (with whom the relationship nificant relationship. †No financial benefit. 